Special issue of the 2nd International Conference on Computational and Experimental Science and Engineering (ICCESEN 2015)

\title{
A New System Design for Energy Management in HVAC Control Systems for Textile Plants
}

\author{
M. IMAL* \\ Kahramanmaras S.I. University, Mech. Eng. Dept., Kahramanmaras, Turkey
}

\begin{abstract}
Good HVAC control is often the most cost-effective option to improve the energy efficiency of a factory. The effect of the control strategy and energy efficiency is usually difficult to predict. To achieve this easily, a fully automated energy saving controller system was designed for heating, ventilating and air-conditioning (HVAC) systems in textile factories. The new designed HVAC control system reduces the energy consumption by $45 \%$. These control system can be implemented in the factories with a direct payback period approximately 4 months.
\end{abstract}

DOI: 10.12693/APhysPolA.130.245

PACS/topics: 88.05.Sv, 88.05.Vx

\section{Introduction}

HVAC units used in textile plants have high energy consumptions. It has been estimated that $40 \%$ of total energy is consumed in HVAC systems for textile plants. Therefore, the energy efficiency is the most important role played in HVAC systems. So, a well-designed energy control system improves the energy efficiency [1-4].

In recent years, many researchers have studied dynamic models of HVAC systems and their components using theoretical or experimental approaches. The HVAC systems are composed of a large number of subsystems, each of them may exhibit nonlinear characteristics. The parameters of the systems change with weather, load and building occupancy. In many situations, the exact model of the system cannot be obtained, but the approximate model can be derived. These complexities can be eliminated by using a well-designed control technique $[5,6]$.

In this paper, an integrated energy saving HVAC control system was developed for fabric manufacturing plants in textile industry. The designed control system has been used in ARSAN ${ }^{\mathrm{TM}}$ group which is one of the biggest fabric textile companies in Turkey. Every HVAC system has been controlled depending on four parameters; humidifier pump controller for humidification, fresh and bypass damper controllers for temperature control, exhaust fan controllers for stability of differential air pressure and ventilation fan controllers for air flow capacity. Supervisory control software was developed to analyze and to control the whole system from a HMI interface. In addition, energy and mass balance equations are applied to derive a dynamic model HVAC system and a simulation example has been proposed to investigate different control algorithms on the derived mathematical model of the controlled zone.

*e-mail: muharremimal@ksu.edu.tr

\section{System}

The system has such main components as an air conditioned room of fabric plant, the fresh, bypass and exhaust air dampers, damper actuators, ventilation and exhaust air fans, humidifiers pumps, driver inverters for humidification, temperature, humidity, air flow and differential air pressure sensors and controllers. Figure 1 shows the general schematic diagram of the single-zone HVAC controlled system for textile plants. The ideal temperature and humidity levels are generally $25^{\circ} \mathrm{C}$ and $70 \%$, respectively, in textile air condition systems.

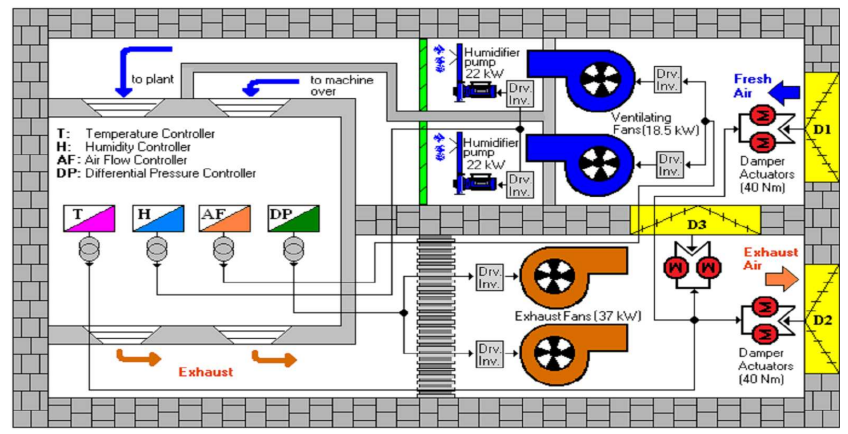

Fig. 1. General block diagram of the controlled HVAC system for textile plants.

Cooling process is performed by utilizing the cold water used for humidification by mixing fresh air supplied from outdoor damper in the textile air condition systems. Heating processes has been made by circulation of indoor air that generated heat from machines, lights and people etc. using bypass dampers. According to desired temperature value, if the controlled zone temperature is to be raised, the controller commands to the bypass dampers in the direction of opening position. Humidity controlling has been performed by using humidifier pumps and its driver inverters having the power of $22 \mathrm{~kW}$, spray water flow rate of $78 \mathrm{~m}^{3} / \mathrm{h}$ and nozzle pressure of $2.1 \mathrm{bar}$.

Air flow controller unit controls the desired volume flow rate of supplied air which is determined from the 
air changes per second for the need of controlled plant. The air flow capacity changes depending on the plant's size, the number of machines and the type of the plant such as fabric or yarn. Energy consumed by the ventilation and exhaust fans corresponds to $40 \%$ of total energy spent in a plant. To decrease energy consumption, the driver inverters have been used for speed control of ventilation and exhaust fans drivers according to desired air flow capacity and differential air pressure in the designed control system.

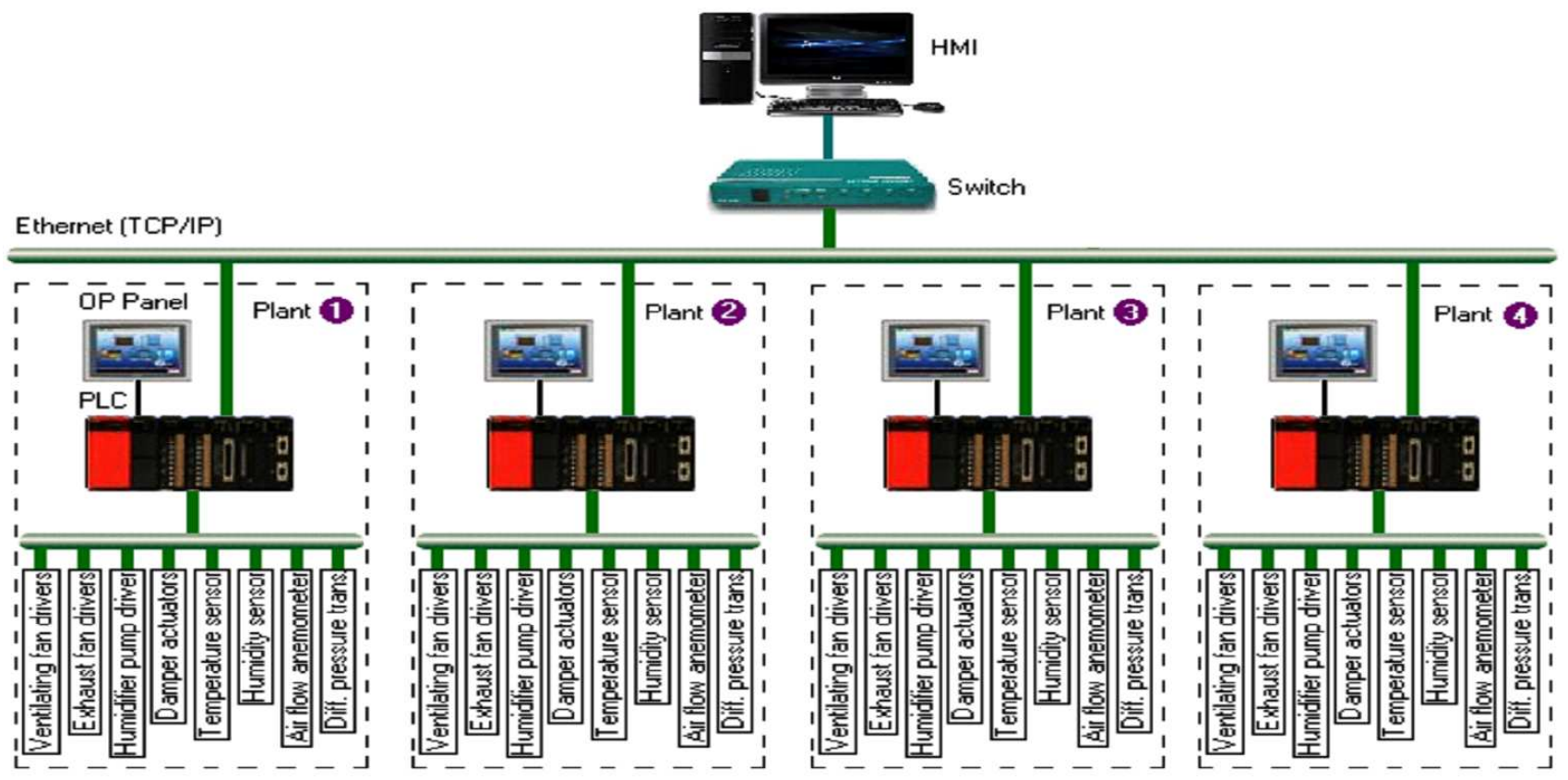

Fig. 2. The developed program form for control and analysis from one HMI unit.

Four independent controllers were designed for each HVAC units as shown in Fig. 2. The whole system has been controlled by the developed supervisory control software from a single control point. The developed supervisory control software is able to perform online data visualization, data storage, data trends, and animation graphs and full control of complete system.

\subsection{Model of heating ventilating and air-conditioning system}

Since the HVAC zones have the structure of complex thermal system structure and the actual air-conditioning system is more variable, it is very difficult to determine for its exact model, but the approximate overall dynamic model of a single-zone HVAC system consisting of all its component models can be derived. According to energy balance equation of system, a simple energy equation for a single-zone HVAC system can be written in Eq. (1):

$Q_{\text {input }}+Q_{\text {generation }}=Q_{\text {out }}+Q_{\text {accumulation }}+Q_{\text {consumption }},(1)$ where $Q_{\text {input }}$ - heat from supply air input, $Q_{\text {generation }}-$ generated heat from people, woven machines, light etc., $Q_{\text {out }}$ - heat from exhaust air, $Q_{\text {accumulation }}$ - indoor space heat, $Q_{\text {consumption }}$ - dissipated heat from indoor to outdoor.

The heat equation is derived from the first law of thermodynamics and conservation of energy. Any change in energy $\Delta Q$ is proportional to the change in temperature $\Delta T$. That is,

$$
\Delta Q=f_{\mathrm{a}} c_{p} \rho_{\mathrm{a}} \Delta T
$$

where $f_{\mathrm{a}}\left(\mathrm{m}^{3} / \mathrm{s}\right)$ is volume flow rate of air, $c_{p}(\mathrm{~kJ} /(\mathrm{kg} \mathrm{K}))$ is the constant pressure specific heat capacity of air and $\rho_{\mathrm{a}}\left(\mathrm{kg} / \mathrm{m}^{3}\right)$ is the mass density of air.

From the thermodynamic heat equations, the fresh and exhaust heat equations can be written as

$$
\begin{aligned}
& Q_{\text {input }}=f_{\mathrm{sa}} c_{\mathrm{pa}} \rho_{\mathrm{a}} T_{\mathrm{sa}}, \\
& Q_{\text {out }}=f_{\mathrm{sa}} c_{\mathrm{pa}} \rho_{\mathrm{a}} T_{i},
\end{aligned}
$$

where $f_{\mathrm{sa}}\left(\mathrm{m}^{3} / \mathrm{s}\right)$ is volume flow rate of supplied air.

$$
Q_{\text {generation }}=Q_{\text {room }},
$$

where $Q_{\text {room }}(\mathrm{W})$ is heat gains from machines, light and people etc.

$$
\begin{aligned}
Q_{\text {accumulation }} & =\rho_{\mathrm{a}} c_{\mathrm{pa}} v_{z} \frac{\mathrm{d} T_{i}}{\mathrm{~d} t}, \\
Q_{\text {consumption }} & =\frac{v_{z} c_{\mathrm{pa}} \mathrm{ACH}}{3600}\left(T_{i}-T_{0}\right),
\end{aligned}
$$

where $v_{z}\left(\mathrm{~m}^{3}\right)$ is volume of the zone. $\mathrm{ACH}$ is the air changes per hour. There are three mode of consumption heat from indoor to outdoor: conduction, convection, and radiation.

The temperature zone equation can be written as

$$
\begin{gathered}
v_{z} c_{\mathrm{pa}} \rho_{\mathrm{a}} \frac{\mathrm{d} T_{i}}{\mathrm{~d} t}=\frac{v_{z} c_{\mathrm{pa}} \mathrm{ACH}}{3600}\left(T_{0}-T_{i}\right) \\
+f_{\mathrm{sa}} c_{\mathrm{pa}} \rho_{\mathrm{a}}\left(T_{\mathrm{sa}}-T_{i}\right)+Q_{\mathrm{room}} .
\end{gathered}
$$

Temperature controlling has been performed by the three damper controller units in the textile HVAC systems 
which are fresh damper, exhaust damper and return air damper. Therefore, supply air volume flow rate is composed of mixing the returned air from inner (exhaust air) zone and outdoor air. This mixing equation can be written from mass balance equation

$$
m_{\mathrm{r}} c_{\mathrm{pa}} T_{i}+m_{\mathrm{o}} c_{\mathrm{pa}} T_{0}=m_{\mathrm{s}} c_{\mathrm{pa}} T_{\mathrm{sa}},
$$

where $m_{\mathrm{r}}, m_{\mathrm{o}}, m_{\mathrm{s}}$ are mass flow rates of the return, outdoor and supplied airs, respectively. This condition has to be fulfilled by the controlling of these three damper positions. Humidification is a mass transfer process of water vapor to atmospheric air, which results in an increase of water vapor in the mixture. Humidifier model is the same as temperature model and can be derived from mass and energy balance principles as given in Eq. (10) [4].

$$
c_{\mathrm{h}} \frac{\mathrm{d} T_{\mathrm{h}}}{\mathrm{d} t}=f_{\mathrm{sa}} c_{\mathrm{pa}}\left(T_{\mathrm{sa}}-T_{\mathrm{h}}\right)+\alpha_{\mathrm{h}}\left(T_{0}-T_{\mathrm{h}}\right),
$$

where $C_{\mathrm{h}}$ is overall thermal capacitance of the humidifier, $T_{\mathrm{h}}$ is supply air temperature (in humidifier), $\alpha_{\mathrm{h}}$ is overall transmittance area factor of the humidifier $(\mathrm{kJ} /(\mathrm{s} \mathrm{K}))$. Similarly, the rate change of moisture content in the zone is equal to the difference between the vapor added to and removed from the zone. Therefore, humidity zone equation can be written in Eq. (11):

$$
v_{z \mathrm{~h}} \frac{\mathrm{d} W_{\mathrm{h}}}{\mathrm{d} t}=f_{\mathrm{sa}}\left(W_{\mathrm{sa}}-W_{\mathrm{h}}\right)+\frac{h(t)}{\rho_{\mathrm{a}}},
$$

where $v_{z \mathrm{~h}}$ is the volume of humidifier, $W_{\mathrm{h}}$ is supply air humidity ratio (in humidifier) in $\mathrm{kg} / \mathrm{kg}$ (dry air), $W_{\mathrm{sa}}$ is humidity ratio of supply air (to the humidifier) in $\mathrm{kg} / \mathrm{kg}$ (dry air), $h(t)$ is the rate of moisture air produced in air humidifier.

In order to simplify Eq. (8), $\tau$ and $k$ can be defined as following:

$$
\begin{aligned}
& \tau=\frac{3600 v_{z} \rho_{\mathrm{a}} m_{\mathrm{s}}}{m_{\mathrm{s}}\left(v_{z} \mathrm{ACH}+3600 f_{\mathrm{sa}} \rho_{\mathrm{a}}\right)-3600 f_{\mathrm{sa}} \rho_{\mathrm{a}} m_{\mathrm{r}}}, \\
& k=\frac{m_{\mathrm{s}} v_{z} \mathrm{ACH}+3600 f_{\mathrm{sa}} \rho_{\mathrm{a}} m_{\mathrm{o}}}{m_{\mathrm{s}}\left(v_{z} \mathrm{ACH}+3600 f_{\mathrm{sa}} \rho_{\mathrm{a}}\right)-3600 f_{\mathrm{sa}} \rho_{\mathrm{a}} m_{\mathrm{r}}} .
\end{aligned}
$$

Finally, temperature zone Eq. (8) has been simplified as

$$
\tau \frac{\mathrm{d} T_{i}}{\mathrm{~d} t}+T_{i}=k T_{0}+Q_{\mathrm{room}}
$$

Because of the distance between supply air and the measurement point of temperature, there is pure delay time $(L)$ in the process. The plant heat transfer function is expressed as follows:

$$
G_{p}(s)=\frac{T_{i}(s)}{T_{0}(s)}=\frac{k \mathrm{e}^{-L s}}{\tau s+1} .
$$

Substituting these parameters to the calculation of $\tau$ and $k$ constants, the transfer function of the plant is determined as below:

$$
G_{p}(s)=\frac{1 \mathrm{e}^{-20 s}}{300 s+1} .
$$

Totally four of the plants having the area of $28.000 \mathrm{~m}^{3}$ has been controlled by using PI controller. The parameters of the biggest zone are as follows:

$$
G(s)=G_{c}(s) G_{p}(s)=K_{p}\left(1+\frac{1}{T_{i} s}\right) \frac{1 \mathrm{e}^{-20 s}}{300 s+1} .
$$

If the model of the system can be obtained, it is easy to design the PID controller for it. The gain coefficients $K_{p}$, and $T_{i}$ can be achieved model based algorithms [7].

\subsection{Experimental results and discussion}

Modern process control problems in the textile industries are dominated by nonlinear, time-varying behavior, disturbances and uncertainties. However, more than $90 \%$ plants are controlled by the well-established controllers in industrial automation and process until today $[8,9]$. Totally 22 controllers were developed in a single Programmable Controller. A software program was developed for quickly tuning the parameters of the controllers. The developed software is able to communicate with the programmable controller, selectable of control type (auto/manual control), able to store control output data into database system and perform on-line analysis graphically. The following experiments have been carried out to observe the performance of the controlled system.

The old conventional control system, exhaust and ventilating fans had been driven by directly at constant speed. The differential pressure sensors, anemometers and driver inverters for exhaust and ventilating fans have been added to the new designed control system. Before the design of control system, the overall energy consumption was measured by using energy analyzer to determine the rate of energy saving of the designed four HVAC systems.

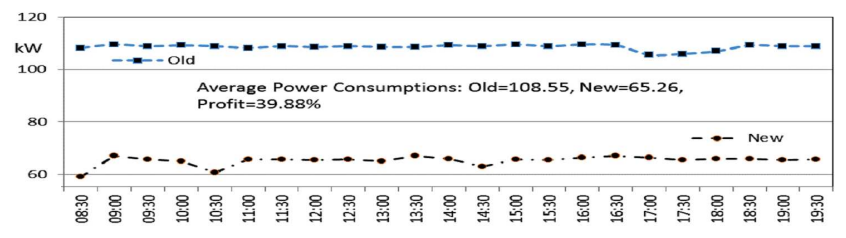

Fig. 3. Energy saving in plant 1.

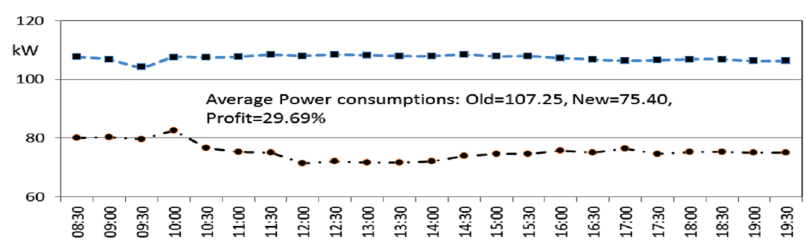

Fig. 4. Energy saving in plant 2.

Figures 3 to 6 show the amount of energy saving data for each controlled plants. Figure 3 shows the energy consumptions for plant 1 , before and after the controller design. The energy consumption in old conventional control system for plant 1 was measured as the average of $118 \mathrm{~kW}$. The energy consumption in the new designed system, this value was decreased to average of $72 \mathrm{~kW}$. The energy saving has been obtained as $46 \mathrm{~kW}$ per hour for plant 1. The energy saving of $41 \mathrm{~kW}$ has been obtained for plant 2, $46 \mathrm{~kW}$ in plant 3 and $39 \mathrm{~kW}$ in plant 4 , respectively. The money spent for plant 1 , plant 2 , and 
plant 3 was approximately 42150 USD and 10550 USD for plant 4. The total energy saving has been measured as $172 \mathrm{~kW}$. The total cost of 52700 USD has been spent on the whole system.

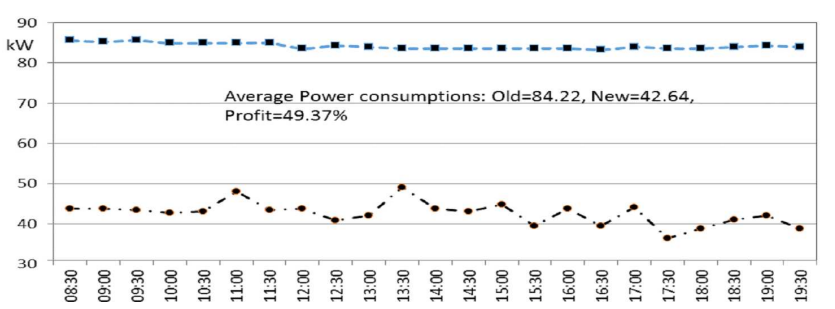

Fig. 5. Energy saving in plant 3 .

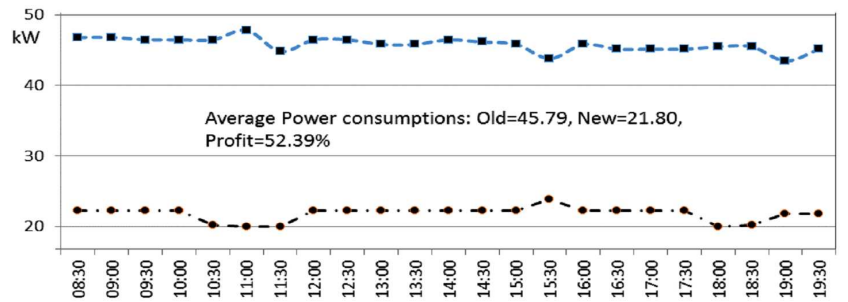

Fig. 6. Energy saving in plant 4 .

\section{Results}

In this study, a HVAC control system has been successfully designed and the dynamic model of the controlled zone has been derived accurately for a big textile fabric plant in Turkey. The simulation and the real controller responses have been observed, respectively. When the results have been compared, either of the system responses has been obtained as similar. Supervisory control software was developed to control overall system using a host computer and programmable controllers. Thus, the system parameters could be observed and controlled on the single central point by the host computer and an operator.
The approximately $45 \%$ energy saving was gained by the designed control system. This energy saving amount was clearly verified by measuring of energy consumption of each plant as shown in Figs. 3 to 6 . Finally the following beneficial results have been obtained:

- Total money spent to control system $=52700 \$$;

- Total energy saving per hour $=172 \mathrm{~kW}$;

- $1 \mathrm{~kW}$ Electricity cost $=0.087 \$ / \mathrm{kWh}$;

- Energy saving per month $=172 \mathrm{kWh} \times 24 \mathrm{~h} \times$ 30 day $\times 0.087 \$ / \mathrm{kWh}=10775 \$$;

- Depreciation time of the system $=52700 / 10775$ $=4.85$ month.

\section{References}

[1] G.P. Henze, D.E. Kalz, S. Liu, C. Felsmann, HVACER Res. 11, 189 (2005).

[2] W.Z. Huang, M. Zaheeruddin, S.H. Cho, En. Convers. Manag. 47, 926 (2006).

[3] S. Soyguder, H. Ali, En. Build. 41, 814 (2009).

[4] B. Tashtoush, M. Molhim, M. Al-Rousan, Energy 30, 1729 (2005).

[5] J. Teeter, M.-Y. Chow, IEEE Trans. Ind. Electron. 45, 170 (1998).

[6] J. Wang, C. Zhang, Y. Jing, in: Proc. IEEE Int. Conf. on Mechatronics and Automation, Takamatsu (Japan), IEEE, New York 2008, p. 677.

[7] D. Xue, Y.Q. Chen, D.P. Atherton, SIAM's Advances in Design and Control Series, Society for Industrial and Applied Mathematics, Philadelphia 2007, p. 181.

[8] N.J. Killingsworth, M. Krstic, IEEE Control Syst. Mag. 26, 70 (2008).

[9] L.H.D. Peiyong, J. Lei, in: Proc. 7th Int. Conf. on Intelligent Control and Automation, Chongqing (China), 2008, p. 736. 